\title{
Relation between metabolic syndrome and body compositions among Chinese adolescents and adults from a large-scale population survey
}

Tao Xu', Junting Liu², Junxiu Liử, Guangjin Zhu and Shaomei Han ${ }^{1 *}$

\begin{abstract}
Background: Few nationally representative surveys regarding body composition and metabolic syndrome (MetS) have been done in a large-scale representative Chinese population to explore the prediction of body composition indicators for MetS. The objective of this study was to examine the relation of body composition and MetS and to determine the optimal cut-off values of body composition indicators that predict MetS in a large representative Chinese sample based on multiple provinces and ethnicities, covering a broad age range from 10 to 80 years old.

Methods: The subjects came from a large-scale population survey on Chinese physiological constants and health conditions conducted in six provinces. 32,036 subjects completed all blood biochemical testing and body composition measure. Subjects meeting at least 3 of the following 5 criteria qualify as having MetS: elevated blood pressure, lower high density lipoprotein cholesterol level, higher triglyceride level, higher fasting glucose level and abdominal obesity.

Results: The total prevalence rate of MetS for males (9.29\%) was lower than for females (11.58\%). The prevalence rates were $12.03 \%$ for male adults and $15.57 \%$ for female adults respectively. The risk of MetS increased $44.6 \%$ $(\mathrm{OR}=1.446,95 \% \mathrm{Cl}: 1.414-1.521)$ for males and $53.4 \%(\mathrm{OR}=1.534,95 \% \mathrm{Cl}: 1.472-1.598)$ for females with each $5 \%$ increase of percentage of body fat. The risk of MetS increased two-fold $(\mathrm{OR}=2.020,95 \% \mathrm{Cl}$ : 1.920-2.125 for males; $\mathrm{OR}=2.047,95 \% \mathrm{Cl}: 1.954-2.144$ for females respectively) with each $5 \%$ increase of waist-hip ratio. The risk of MetS increased three-fold $(\mathrm{OR}=2.915,95 \% \mathrm{Cl}: 2.742-3.099$ for males; $\mathrm{OR}=2.950,95 \% \mathrm{Cl}$ : 2.784-3.127 for females respectively) with each $5 \%$ increase of Waist-to-Height Ratio (WHtR). Areas under the receiver operating curve (AUC) of most body composition indicators were larger than 0.70 and the sensitivities and the specificities of most cut-off values were larger than 0.65. AUCs of WHR and WHtR were the largest. The optimal cut-off values of WHtR were 0.51 for males and 0.53 for females.
\end{abstract}

Conclusion: MetS has become a serious public health challenge in China. Body composition variables were closely related to MetS and they were reliable indicators in the screening of the presence of MetS.

Keywords: Metabolic syndrome, Body composition, Percentage of body fat, Body mass index, Waist-to-height ratio, Screening

\footnotetext{
* Correspondence: hansm1@vip.sina.com

${ }^{1}$ Institute of Basic Medical Sciences, Chinese Academy of Medical Sciences \&

School of Basic Medicine, Peking Union Medical College, Beijing 100005,

China

Full list of author information is available at the end of the article
} 


\section{Background}

As a result of economic growth and associated sociodemographic changes, the burden from infectious diseases has diminished in China, but changes in lifestyle and diet have led to an increase in life expectancy and an increased burden of cardiovascular disease, diabetes and other chronic diseases [1-3]. Metabolic syndrome (MetS) is characterized by a clustering of cardiovascular risk factors, including abdominal obesity, elevated blood pressure and blood glucose, and dyslipidemia. MetS has been found to be associated with an increased risk of diabetes and cardiovascular disease morbidity and mortality, resulting in an enormous economic burden to society [4-7]. In China, Feng Y surveyed the prevalence of MetS among a rural population of one Chinese province [8]. Gu D reported that the prevalence rates of MetS were $9.8 \%$ for males and $17.8 \%$ for females in Chinese adults aged 35-74 [9]. Even with all of this information, more evidence is needed regarding the prevalence rate of MetS among representative Chinese populations that cover a broader age range and that include more minorities and provinces.

Excess body fat has been seen to be related to MetS [10]. Visceral adiposity was associated with body mass index (BMI), was essential to assess cardiometabolic risk and may serve as a marker and target of therapy in cardiometabolic disease [11]. Djibo DA found that body adiposity index could distinguish ethnic differences in MetS confirmed by percentage of body fat (PBF) [12]. Zhu S reported PBF thresholds that corresponded to the risk of MetS based on traditional BMI cutoffs and provided equations for estimating the risk of MetS for any given percentage of body fat, sex, and race [13]. Liu P found that higher fat mass index (FMI) levels appeared to be independently and positively associated with the presence of MetS regardless of BMI and PBF by assessing the body composition in a Chinese population who participated in the annual health check-ups in one hospital [14]. However, few nationally representative surveys on the relationship between body composition and MetS have been done in a large-scale representative Chinese population to explore the prediction validity of body composition indicators for MetS.

The objective of this study was to examine the relationship between body composition and MetS and to determine the optimal cut-off values of body composition indicators to predict MetS in a large representative sample of Chinese adolescents and adults based on multiple provinces and ethnicities, covering a broad age range from 10 to 80 years old.

\section{Methods}

\section{Sample and participants}

This study sample was part of a large-scale population survey regarding Chinese physiological constants and health conditions conducted in 2007-2011. The study has been approved by the review board of Institute of Basic Medical Sciences, Chinese Academy of Medical Sciences. This survey was carried out in six provinces of China, including Heilongiiang province, Hunan province, Sichuan province, Yunnan province, Inner Mongolia autonomous region and Ningxia Hui autonomous region. The two-stage cluster sampling method was used to select eligible subjects in each province. Two or three cities were sampled based on their economical status and then several communities were randomly selected within each city. In these selected communities, all eligible people were referred to as our survey subjects. Eligible people included those aged 10-80 years old who weren't suffering from severe chronic diseases and had not run a high fever in the past 15 days. After signing informed consent forms, all subjects came to the temporary physical examination centers voluntarily to take part in the survey. Among 82,336 eligible subjects, 34,903 people $(42.4 \%)$ were selected randomly to complete blood biochemical testing. After excluding subjects missing important measures, such as biochemical variables and body composition indicators, 32,036 subjects had complete data on all survey scales, blood biochemical testing and body composition measures. The completion rate was $91.8 \%$.

\section{Clinical laboratory tests}

A team of experienced doctors, nurses, and technicians performed measurements of study parameters with standard laboratory methods. All procedures were performed following a 9-12 h overnight fast and all subjects were told to consume a bland diet before blood testing. Blood samples were drawn from the antecubital vein of the arm. Total cholesterol, triglycerides, high-density lipoprotein cholesterol and lowdensity lipoprotein cholesterol were measured with a Beckman AU Series Automatic Biochemical Analyzer (Japan), using Sekisui Medical (Japan) reagents. Fasting blood glucose, uric acid, creatine, and blood urea nitrogen were measured with the same instrument, using Beckman AU reagents.

\section{Body composition}

Body composition was measured with the bioelectric impedance method (BIA). The Biodynamics BI-310 body composition analyzer was manufactured by American Biodynamics Corporation with high sensitivity and specificity. The same brand and model was used for all body composition analyzers and were adjusted every day before measuring in order to minimize measurement error. All researchers were trained based on the training manual. Subjects were to fast, refrain from strenuous exercise, at least $4 \mathrm{~h}$ before measuring and refrain from 
drinking $24 \mathrm{~h}$ before measuring. When measuring, subjects were in a supine position, hands were placed flatwise away from their body $15 \mathrm{~cm}$, and feet were kept apart at least $15 \mathrm{~cm}$.

Body composition indicators included percentage of body fat (PBF), body mass index (BMI), fat mass index (FMI) and fat-free mass index (FFMI), Waist-to-Hip Ratio (WHR) and Waist-to-Height Ratio (WHtR). PBF was the proportion of body fat weight in total body weight. BMI was defined as weight $(\mathrm{kg})$ divided by squared height $\left(\mathrm{m}^{2}\right)$. FMI was defined as fat body mass $(\mathrm{kg})$ divided by squared height $\left(\mathrm{m}^{2}\right)$. FFMI was defined as lean body mass $(\mathrm{kg})$ divided by squared height $\left(\mathrm{m}^{2}\right)$. WHR was defined as waist circumference divided by hip circumference. WHtR was defined as waist circumference divided by height. All mass indexes were measured to the nearest $0.1 \mathrm{~kg}$.

\section{Blood pressure measurement}

Blood pressure was measured in the morning after subjects had rested for $5 \mathrm{~min}$ in the seating position with her or his back supported, feet on the floor and right arm supported with cubit fossa at heart level. The appropriate cuff was chosen based on their arm circumference. Blood pressure was measured based on one clinical visit with OMRON HEM-7000 electronic sphygmomanometers (OMRON Health-Care, Kyoto, Japan).

\section{Definition of metabolic syndrome}

According to the National Cholesterol Education Program Adult Treatment Panel III (NCEP ATP III), persons meeting at least 3 of the following 5 criteria qualify as having MetS: higher fasting glucose level, elevated blood pressure, lower high density lipoprotein cholesterol (HDL-C) level, higher triglyceride level and abdominal obesity $[15,16]$. The definitions are shown below in detail.

For adults:

1) Elevated blood glucose: fasting blood glucose $\geq 110 \mathrm{mg} / \mathrm{dL}$ or diagnosed diabetes;

2) Elevated blood pressure (systolic blood pressure $\geq 130 \mathrm{mmHg}$ and/or diastolic blood pressure $\geq 85 \mathrm{mmHg}$ ) or history of hypertension;

3) Low HDL-C: serum HDL-C concentration $<40 \mathrm{mg} / \mathrm{dL}$ for males and $<50 \mathrm{mg} / \mathrm{dL}$ for females;

4) Elevated triglyceride: serum triglyceride concentration $\geq 150 \mathrm{mg} / \mathrm{dL}$;

5) Abdominal obesity: a waist circumference of $\geq 102 \mathrm{~cm}$ for males and $\geq 88 \mathrm{~cm}$ for females, as measured to the nearest $0.1 \mathrm{~cm}$ at the level of the navel, using a flexible steel tape.
For adolescents:

1) Elevated blood glucose: fasting blood glucose $\geq 110 \mathrm{mg} / \mathrm{dL}$ or diagnosed diabetes; 2) Elevated blood pressure: elevated blood pressure (systolic blood pressure $\geq 90$ th percentile and/or diastolic blood pressure $\geq 90$ th percentile by age and sex) or history of hypertension;

2) Low HDL-C: serum HDL-C concentration $<40 \mathrm{mg} / \mathrm{dL}$;

3) Elevated triglyceride: serum triglyceride concentration $\geq 110 \mathrm{mg} / \mathrm{dL}$;

4) Abdominal obesity: a waist circumference $\geq 90$ th percentile by age and sex.

5) The 90th percentiles of waist circumference and blood pressure came from the age- and sex-specific reference data established by the survey among Chinese adolescents $[17,18]$.

\section{Statistical analysis}

The database was constructed with EPI3.02 software, with the data input twice by two data managers to guarantee the accuracy and integration of the data. Statistical analysis was conducted with SAS9.2 software. Twotailed $P<0.05$ was defined as statistically significant. Continuous data were described with mean and standard deviation (SD) and compared with $t$ test analysis of variance. Categorical data were described with number and percentage and compared with Chi-square test. Logistic regression model was used to estimate odds ratio (OR) and its $95 \%$ confidence interval $(\mathrm{CI})$ for exploring the relation between body metabolic measures and MetS with sociodemographic factors as covariates. Receiver operating curve (ROC) analyses were used to determine optimal cutoff points for PBF, BMI, FMI, FFMI, WHR and WHtR in relation to the area under the curve (AUC), sensitivity and specificity in males and females. The values of PBF, BMI, FMI, FFMI, WHR and WHtR that resulted in maximizing the Youden index (sensitivity + specificity-1) were defined as optimal cutoff points.

\section{Results}

The average age was $32.9 \pm 19.5$ years for 15,272 males and $33.3 \pm 18.9$ years for 16,764 females. The subjects came from dozens of ethnicities, including Han $(19,564$, 61.0\%), Yi (2830, 9.0\%), Miao (603, 2.0\%), Mongolia (2026, 7.0\%), Tibetan (1243, 4.0\%), Korean (1514, 5.0\%), Hui $(2973,10.0 \%)$, Tujia $(816,3.0 \%)$ and others (467, $2.0 \%)$.

Of all 32,036 subjects, $60.73 \%$ of all subjects $(N=19,499)$ had at least one clinical feature of MetS ( 1 or more risk factors). 33.71\%, 16.69\%, 7.72\%, $2.38 \%$ and $0.37 \%$ of all subjects had one, two, three, four and five risk factors respectively. Risk factors in 
order of prevalence were elevated blood pressure (37.52\%), elevated triglyceride (22.53\%), low HDL-C (21.18\%), elevated blood glucose (10.63\%) and abdominal obesity $(9.86 \%)$. The most prevalent grouping of two risk factors was blood pressure and low HDL-C (7.10\%). The most prevalent grouping of three risk factors was elevated blood pressure, elevated triglyceride and low HDL-C (3.83\%).

All in all, 3354 subjects were diagnosed as MetS and the prevalence rate was $10.47 \%$. The prevalence rate of MetS for males (9.29\%) was lower than females (11.58\%). Among 20, 862 adults (aged 18 years old or above), 2926 ones were diagnosed as MetS and the prevalence rate was $14.03 \%$. The prevalence rates of MetS were $12.03 \%$ for male adults and $15.57 \%$ for female adults respectively. The prevalence and related factors of MetS as related to different demographic characteristics were shown in details in Table 1. With aging, the prevalence rates increased gradually. Among minorities, Tibetan subjects held the lowest prevalence rate of MetS and Korean subjects the highest one.

Given that there were significant differences of body composition indicators and MetS between the two genders, analyses on the relationship between body composition indicators and MetS was conducted on males and females separately. Table 2 indicates the comparisons of body composition indicators between subjects with MetS and without MetS by genders. PBF of subjects with MetS was significantly higher than those without MetS (21.08\% VS $14.58 \%$ for males; $30.08 \%$ VS $22.9 \%$ for females). WHtR of subjects with MetS was significantly higher than those without MetS (0.54 VS 0.46 for males; 0.56 VS 0.46 for females). In addition, subjects without MetS had higher BMI, FMI, FFMI and WHR.

Table 3 shows the ORs and their 95\%CI of body composition indicators predicting MetS with various logistic regression models. The similar trend was found regarding the relationship between body composition indicators and MetS in two genders and two models. We found the risk of MetS would increase 44.6\% (OR $=1.446$, 95\%CI: $1.414-1.521)$ for males and $53.4 \%(\mathrm{OR}=1.534$, 95\%CI: 1.472-1.598) for females with each 5\% increase of PBF adjusting for age, gender, ethnicity, occupation, smoking and drinking with multivariate logistic models. Adjusting for the same demographic characteristics, the risk of MetS would increase $40.7 \%(\mathrm{OR}=1.407,95 \% \mathrm{CI}$ : $1.380-1.434)$ for males and $38.9 \%(\mathrm{OR}=1.389,95 \% \mathrm{CI}$ : 1.364-1.415) for females with each $1 \mathrm{~kg} / \mathrm{m}^{2}$ increase of BMI. Meanwhile, the risk of MetS increased two-fold $(\mathrm{OR}=2.020,95 \% \mathrm{CI}: 1.920-2.125$ for males; $\mathrm{OR}=2.047$, 95\%CI: 1.954-2.144 for females respectively) with each $5 \%$ increase of WHR. The risk of MetS increased threefold $(\mathrm{OR}=2.915,95 \% \mathrm{CI}: 2.742-3.099$ for males; $\mathrm{OR}=2.950,95 \% \mathrm{CI}: 2.784-3.127$ for females respectively) that of non-MetS with each 5\% increase of WHtR. ORs and their 95CI of other body compositions were shown in Table 3.

The areas under ROC curve, the cutoff values, and the most appropriate sensitivities and specificities of the indicators are presented separately for adults in Table 4 and adolescents in Table 5. As shown in Tables 4 and 5, the AUCs of most body composition indicators were larger than 0.70 and the sensitivities and the specificities of most cut-off values were larger than 0.65 . For adults, the AUC of WHR (0.809 for males and 0.818 for females) and the AUC of WHtR $(0.824$ for males and 0.759 for females) were larger than those of other body composition indicators. The optimal cut-off values of WHR were 0.89 for males and 0.84 for females. The optimal cut-off values of WHtR were 0.51 for males and 0.53 for females. The optimal cut-off value of PBF for males was $17.78 \%$ which was smaller by about $10 \%$ than for females (27.45\%). For adolescents, the AUC of BMI (0.717 for boys and 0.704 for girls) and the AUC of WHtR (0.771 for boys and 0.713 for girls) were larger than those of other body composition indicators. The optimal cut-off values of BMI were $21.95 \mathrm{~kg} / \mathrm{m}^{2}$ for boys and $21.11 \mathrm{~kg} / \mathrm{m}^{2}$ for girls. The optimal cut-off values of WHtR were 0.46 for both boys and girls. The optimal cut-off value of PBF for boys was $14.56 \%$, which was smaller by about $8 \%$ than for girls (22.36\%).

\section{Discussions}

MetS is associated with the development of diabetes, cardiovascular diseases, and kidney diseases, which are the leading cause of mortality worldwide [19-22]. In the present study, we found that the prevalence rate of MetS was $9.29 \%$ for males and $11.58 \%$ for females. Among adults (aged 18 years old or above), the prevalence rate of MetS was $12.03 \%$ for male and $15.57 \%$ for female respectively. As overweight and obesity increased worldwide, MetS itself will also become increasingly common. Without a national emphasis on the prevention and control of the metabolic syndrome, the burden of this problem in China is likely to increase in the near future.

To the best of our knowledge, this is the first study that examined the relationship between body composition variables and MetS as well as determined the optimal cut-off values of body composition variables that predict metabolic syndrome with a large representative Chinese sample including six provinces and many minority groups, covering a broad age range from 10 to 80 years old. Our survey was conducted with standard protocols and instruments and strict training processes and vigorous quality assurance programs were used to ensure the quality of the data collection.

In this study, PBF, BMI, FMI, FFMI, WHR and WHtR were found be closely related with MetS. The AUCs of 
Table 1 Prevalence (\%) of metabolic syndrome about demographic characteristics

\begin{tabular}{|c|c|c|c|c|c|c|c|c|}
\hline $\begin{array}{l}\text { Demographic } \\
\text { characteristics }\end{array}$ & Total & One component & Two components & Three components & Four components & Five components & MetS & $P^{*}$ \\
\hline Age (years) & & & & & & & & $<0.0001$ \\
\hline $10-17$ & 11,174 & 35.51 & 12.49 & 3.00 & 0.77 & 0.06 & 3.83 & \\
\hline $18-29$ & 5198 & 32.90 & 8.77 & 2.15 & 0.42 & 0.02 & 2.60 & \\
\hline $30-39$ & 3940 & 33.10 & 17.08 & 7.26 & 1.45 & 0.18 & 8.88 & \\
\hline $40-49$ & 4327 & 32.89 & 22.65 & 11.72 & 3.00 & 0.35 & 15.07 & \\
\hline $50-59$ & 3654 & 31.86 & 24.66 & 15.68 & 5.77 & 0.74 & 22.19 & \\
\hline $60-69$ & 2478 & 30.31 & 26.11 & 18.04 & 7.87 & 1.53 & 27.44 & \\
\hline $70-80$ & 1265 & 37.87 & 23.16 & 16.92 & 4.90 & 1.74 & 23.56 & \\
\hline Gender & & & & & & & & $<0.0001$ \\
\hline Male & 15,272 & 34.32 & 17.95 & 7.41 & 1.73 & 0.15 & 9.29 & \\
\hline Female & 16,764 & 33.15 & 15.53 & 8.01 & 2.98 & 0.56 & 11.58 & \\
\hline Occupation & & & & & & & & $<0.0001$ \\
\hline Physical laborer & 11,270 & 33.35 & 20.91 & 12.15 & 4.21 & 0.79 & 17.15 & \\
\hline Mental laborer & 20,766 & 33.90 & 14.40 & 5.32 & 1.39 & 0.13 & 6.84 & \\
\hline Ethnicity & & & & & & & & $<0.0001$ \\
\hline Han & 19,564 & 32.59 & 16.58 & 8.30 & 2.68 & 0.42 & 11.40 & \\
\hline Yi & 2830 & 40.32 & 17.99 & 5.97 & 1.31 & 0.18 & 7.46 & \\
\hline Miao & 603 & 30.18 & 13.60 & 5.47 & 1.82 & 0.00 & 7.30 & \\
\hline Mongolia & 2026 & 31.34 & 15.89 & 7.65 & 1.78 & 0.25 & 9.67 & \\
\hline Tibetan & 1243 & 34.35 & 11.34 & 3.30 & 1.05 & 0.24 & 4.59 & \\
\hline Korean & 1514 & 33.55 & 17.70 & 8.85 & 2.91 & 0.33 & 12.09 & \\
\hline Hui & 2973 & 37.50 & 19.58 & 7.97 & 2.62 & 0.50 & 11.10 & \\
\hline Tujia & 816 & 33.46 & 15.81 & 6.13 & 1.23 & 0.12 & 7.48 & \\
\hline Others & 467 & 30.41 & 14.78 & 6.64 & 2.14 & 0.00 & 8.78 & \\
\hline Smoker & & & & & & & & $<0.0001$ \\
\hline No & 26,223 & 33.58 & 15.83 & 7.17 & 2.31 & 0.39 & 9.87 & \\
\hline Yes & 5813 & 34.30 & 20.54 & 10.22 & 2.68 & 0.28 & 13.18 & \\
\hline Alcohol drinker & & & & & & & & $<0.0001$ \\
\hline No & 26,371 & 33.68 & 15.65 & 7.17 & 2.32 & 0.39 & 9.88 & \\
\hline Yes & 5665 & 33.84 & 21.50 & 10.27 & 2.67 & 0.26 & 13.20 & \\
\hline
\end{tabular}

${ }^{*} P$ values were derived from chi-square test for compare the difference of the prevalence rates of MetS among different demographic characteristics

Table 2 Comparisons of body composition indicators between MetS and Non-MetS

\begin{tabular}{|c|c|c|c|c|c|c|}
\hline & \multicolumn{3}{|l|}{ Male } & \multicolumn{3}{|l|}{ Female } \\
\hline & $\overline{\text { MetS }}$ & Non-MetS & $P^{*}$ & $\overline{\text { MetS }}$ & Non-MetS & $P^{*}$ \\
\hline PBF (\%) & $21.08 \pm 7.23$ & $14.58 \pm 8.32$ & $<0.0001$ & $30.08 \pm 6.67$ & $22.99 \pm 7.53$ & $<0.0001$ \\
\hline BMI $\left(\mathrm{kg} / \mathrm{m}^{2}\right)$ & $27.00 \pm 3.60$ & $21.74 \pm 3.77$ & $<0.0001$ & $26.18 \pm 3.59$ & $21.38 \pm 3.30$ & $<0.0001$ \\
\hline $\mathrm{FMI}\left(\mathrm{kg} / \mathrm{m}^{2}\right)$ & $21.17 \pm 2.57$ & $18.41 \pm 2.79$ & $<0.0001$ & $18.17 \pm 2.14$ & $16.32 \pm 2.02$ & $<0.0001$ \\
\hline FFMI $\left(\mathrm{kg} / \mathrm{m}^{2}\right)$ & $5.81 \pm 2.36$ & $3.32 \pm 2.18$ & $<0.0001$ & $8.00 \pm 2.48$ & $5.06 \pm 2.17$ & $<0.0001$ \\
\hline WHR & $0.92 \pm 0.06$ & $0.84 \pm 0.07$ & $<0.0001$ & $0.89 \pm 0.07$ & $0.80 \pm 0.06$ & $<0.0001$ \\
\hline WHtR & $0.54 \pm 0.06$ & $0.46 \pm 0.06$ & $<0.0001$ & $0.56 \pm 0.06$ & $0.46 \pm 0.06$ & $<0.0001$ \\
\hline
\end{tabular}

*t-test 
Table 3 ORs and 95\% Cl of body composition indicators for MetS

\begin{tabular}{|c|c|c|c|c|c|c|c|c|}
\hline & \multicolumn{4}{|l|}{ Male } & \multicolumn{4}{|c|}{ Female } \\
\hline & \multicolumn{2}{|c|}{ Univariate } & \multicolumn{2}{|c|}{ Adjusted $^{a}$} & \multicolumn{2}{|c|}{ Univariate } & \multicolumn{2}{|c|}{ Adjusted $^{\mathrm{a}}$} \\
\hline & OR & $95 \% \mathrm{Cl}$ & OR & $95 \% \mathrm{Cl}$ & OR & $95 \% \mathrm{Cl}$ & OR & $95 \% \mathrm{Cl}$ \\
\hline PBF $(5 \%)^{b}$ & 1.516 & $1.468-1.565$ & 1.466 & $1.414-1.521$ & 1.878 & $1.812-1.947$ & 1.534 & $1.472-1.598$ \\
\hline BMI $\left(\mathrm{kg} / \mathrm{m}^{2}\right)$ & 1.414 & $1.390-1.439$ & 1.407 & $1.380-1.434$ & 1.454 & $1.430-1.478$ & 1.389 & $1.364-1.415$ \\
\hline FMI $\left(\mathrm{kg} / \mathrm{m}^{2}\right)$ & 1.459 & $1.426-1.493$ & 1.438 & $1.401-1.476$ & 1.550 & $1.512-1.590$ & 1.502 & $1.459-1.546$ \\
\hline FFMI $\left(\mathrm{kg} / \mathrm{m}^{2}\right)$ & 1.508 & $1.472-1.544$ & 1.464 & $1.426-1.503$ & 1.642 & $1.605-1.679$ & 1.488 & $1.450-1.527$ \\
\hline WHR (5\%) & 2.211 & $2.112-2.315$ & 2.020 & $1.920-2.125$ & 2.509 & $2.406-2.617$ & 2.047 & $1.954-2.144$ \\
\hline WHtR (5\%) & 2.891 & $2.741-3.049$ & 2.915 & $2.742-3.099$ & 3.264 & $3.110-3.426$ & 2.950 & $2.784-3.127$ \\
\hline
\end{tabular}

${ }^{a}$ Adjusting for age, gender, ethnicity, occupation, smoking and drinking with multivariate logistic models

${ }^{b}$ ORs of PBF, WHR and WHtR were the ORs of $5 \%$ of PBF, WHR and WHtR

most body composition indicators were larger than 0.70 and the sensitivities and the specificities of most cut-off values were larger than 0.65 , which showed good predictability of body composition indicators for MetS.

We found the optimal cut-off values of BMI predicting MetS $\left(24.77 \mathrm{~kg} / \mathrm{m}^{2}\right.$ for adults males and $24.33 \mathrm{~kg} / \mathrm{m}^{2}$ for adults females) were almost same as the standard overweight cutoff $\left(24 \mathrm{~kg} / \mathrm{m}^{2}\right)$ for Chinese adults [23]. The optimal cut-off values of WHtR were 0.51 for male adults and 0.53 for adults females, which indicated that a Chinese person may be more susceptible to suffer from MetS when his/her waist circumference is greater than half of his/her height. A previous meta-analysis showed

Table 4 Sensitivity, specificity and AUC in prediction of MetS for adults

\begin{tabular}{llllll}
\hline Indicators & Cut-off value & Sensitivity & Specificity & AUC & $95 \% \mathrm{Cl}$ \\
\hline PBF (\%) & & & & & \\
Male & 17.78 & 0.712 & 0.579 & 0.695 & $0.681-0.709$ \\
Female & 27.45 & 0.747 & 0.649 & 0.745 & $0.733-0.757$ \\
BMl $\left(\mathrm{kg} / \mathrm{m}^{2}\right)$ & & & & & \\
Male & 24.77 & 0.799 & 0.670 & 0.809 & $0.797-0.821$ \\
Female & 24.33 & 0.760 & 0.743 & 0.820 & $0.809-0.830$ \\
FMl (kg/m $\left.{ }^{2}\right)$ & & & & & \\
Male & 20.38 & 0.683 & 0.661 & 0.730 & $0.715-0.745$ \\
Female & 17.62 & 0.643 & 0.682 & 0.714 & $0.701-0.728$ \\
FFMI (kg/m²) & & & & & \\
Male & 4.46 & 0.739 & 0.622 & 0.747 & $0.734-0.761$ \\
Female & 6.91 & 0.727 & 0.745 & 0.799 & $0.788-0.810$ \\
WHR & & & & & \\
Male & 0.89 & 0.809 & 0.620 & 0.781 & $0.769-0.794$ \\
Female & 0.84 & 0.818 & 0.320 & 0.823 & $0.812-0.833$ \\
WHtR & & & & & \\
Male & 0.51 & 0.824 & 0.643 & 0.807 & $0.795-0.819$ \\
Female & 0.53 & 0.759 & 0.798 & 0.856 & $0.847-0.866$ \\
\hline
\end{tabular}

that a reduction of overweight (BMI to $<24 \mathrm{~kg} / \mathrm{m}^{2}$ ) might reduce the incidence of stroke by $15 \%$ in men and $22 \%$ in women in China [24]. Another study also suggested that BMI, waist circumference and WHtR values were all associated with metabolic risk factors, and they may equally predict multiple metabolic risk factors [25]. A Korean study showed that WHtR was a better screening tool than BMI and waist circumference for adult metabolic risk factors was the best screening tool for evaluation MetS in Korean men [26, 27].

The optimal cut-off values of FMI for males were larger by about $2.6 \mathrm{~kg} / \mathrm{m}^{2}$ for adults and $2.0 \mathrm{~kg} / \mathrm{m}^{2}$ for adolescents than those for females. The optimal

Table 5 Sensitivity, specificity and AUC in prediction of MetS for adolescents

\begin{tabular}{llllll}
\hline Indicators & Cut-off value & Sensitivity & Specificity & AUC & $95 \% \mathrm{Cl}$ \\
\hline PBF (\%) & & & & & \\
Male & 14.56 & 0.678 & 0.710 & 0.732 & $0.695-0.769$ \\
Female & 22.36 & 0.637 & 0.773 & 0.697 & $0.660-0.734$ \\
BMI $\left(\mathrm{kg} / \mathrm{m}^{2}\right)$ & & & & & \\
Male & 21.95 & 0.717 & 0.870 & 0.857 & $0.827-0.887$ \\
Female & 21.11 & 0.704 & 0.759 & 0.787 & $0.754-0.820$ \\
FMI (kg/m $\left.{ }^{2}\right)$ & & & & & \\
Male & 18.72 & 0.634 & 0.791 & 0.773 & $0.739-0.807$ \\
Female & 16.67 & 0.610 & 0.741 & 0.721 & $0.685-0.757$ \\
FFMl (kg/m $\left.{ }^{2}\right)$ & & & & & \\
Male & 3.50 & 0.663 & 0.815 & 0.782 & $0.745-0.819$ \\
Female & 4.65 & 0.695 & 0.703 & 0.749 & $0.713-0.785$ \\
WHR & & & & & \\
Male & 0.85 & 0.698 & 0.769 & 0.791 & $0.759-0.823$ \\
Female & 0.80 & 0.671 & 0.687 & 0.730 & $0.697-0.767$ \\
WHtR & & & & & \\
Male & 0.46 & 0.771 & 0.815 & 0.843 & $0.812-0.874$ \\
Female & 0.46 & 0.713 & 0.796 & 0.813 & $0.783-0.844$ \\
\hline & & & & &
\end{tabular}


cut-off values of FFMI for males were smaller by about $2.5 \mathrm{~kg} / \mathrm{m}^{2}$ among adults and $1.1 \mathrm{~kg} / \mathrm{m}^{2}$ among adolescents than those for females. The optimal cutoff value of PBF for male adults was $17.78 \%$, which was smaller by about $10 \%$ than for female adults (27.45\%). The optimal cut-off value of PBF for boys was $14.56 \%$ which was smaller by about $8 \%$ than for girls $(22.36 \%)$. This may be ascribed to the different influence of body fat on the two genders. Body fat mainly inhabits internal organs for males and under subcutaneous tissues for females, which is called ectopic fat disposition [28]. Body fat in internal organs plays a role in impairing insulin resistance $[29,30]$. Visceral adiposity was more strongly associated with incident MetS than subcutaneous fat [11]. Therefore, the cut-off values of PBF and FFMI for females were larger than for males. In addition, females had a much higher prevalence of the MetS than did males. This difference might be due to a higher prevalence of abdominal obesity and low HDL-cholesterol in women compared with men [9].

Several limitations have to be mentioned. First, due to the cross-sectional design, it is not possible to explore the causal relationship between body composition and MetS. Second, given that our analysis excluded subjects suffering from some severe chronic diseases and having fever in the last 15 days, we believe the true prevalence of MetS in Chinese population would be underestimated. Third, subjects in this study did not include children aged $<10$ years old and elders aged $>80$ years old, which should be studied further in future.

\section{Conclusions}

Despite these limitations, our findings showed that MetS has become a serious public health challenge in China. Body composition variables PBF, BMI, FMI, FFMI, WHR and WHtR were closely related with MetS and they were reliable indicators in the screening of the presence of MetS.

\section{Abbreviations \\ AUC: Area under the curve; BMI: Body mass index; Cl: Confidence interval; DBP: Diastolic blood pressure; FFMI: Fat-free mass index; FMI: Fat mass index; HDL-C: High density lipoprotein cholesterol; MetS: Metabolic syndrome; NCEP ATP III: National Cholesterol Education Program Adult Treatment Panel III; OR: Odds ratio; PBF: Proportion of body fat weight; ROC: Receiver operating curve; SBP: Systolic blood pressure; SD: Standard deviation; WC: Waist circumference; WGOC: Working Group on Obesity in China; WHR: Waist-to-Hip Ratio; WHtR: Waist-to-Height Ratio}

\section{Acknowledgements}

We wish to thank all of the subjects who gave their time so generously to participate in the research.

\section{Funding}

This work is supported by the basic performance key project by the Ministry of Science and Technology of the People's Republic of China (No. 2006FY110300).

\section{Availability of data and material}

Data are held at the Institute of Basic Medical Sciences, Chinese Academy of Medical Sciences. All relevant data are within the paper.

\section{Authors' contributions}

XT participated in the design of the study and the field survey, preformed the statistical analysis and drafted the manuscript. LJT participated in the field survey and the blood pressure measurement. LJX took part in the revision and language improvement of the manuscript. ZGJ conceived of the study. HSM conceived of the study and participated in its design. All authors read and approved the final manuscript.

\section{Competing interests}

The authors declare that they have no competing interests.

\section{Consent for publications \\ All participants gave verbal or written consent for their accounts to be anonymously published.}

\section{Ethics approval and consent to participate}

The study has been approved by the review board of Institute of Basic Medical Sciences, Chinese Academy of Medical Sciences. All included subjects gave their informed consent forms to participate in the study.

\section{Publisher's Note}

Springer Nature remains neutral with regard to jurisdictional claims in published maps and institutional affiliations.

\section{Author details}

'Institute of Basic Medical Sciences, Chinese Academy of Medical Sciences \& School of Basic Medicine, Peking Union Medical College, Beijing 100005, China. ${ }^{2}$ Department of Epidemiology, Capital Institute of Pediatrics, Beijing 100020, China. ${ }^{3}$ Tufts Friedman School of Nutrition Science and Policy, 150 Harrison Ave, Boston, MA 02111, USA.

Received: 8 October 2016 Accepted: 6 April 2017

Published online: 20 April 2017

\section{References}

1. Yao C, Wu Z, Wu Y. The changing pattern of cardiovascular diseases in China. World Health Stat Q. 1993;46:113-8.

2. Popkin BM, Horton S, Kim S, Mahal A, Shuigao J. Trends in diet, nutritional status, and diet-related noncommunicable diseases in China and India: the economic costs of the nutrition transition. Nutr Rev. 2001;59:379-90.

3. Yusuf S, Reddy S, Ounpuu S, Anand S. Global burden of cardiovascular diseases: part I: general considerations, the epidemiologic transition, risk factors, and impact of urbanization. Circulation. 2001;104:2746-53.

4. Dou X, Zhang H, Sun $\mathrm{K}$, et al. Metabolic syndrome strongly linked to stroke in Chinese. Natl Med J China. 2004;84:539-42.

5. Lakka HM, Laaksonen DE, Lakka TA, et al. The metabolic syndrome and total and cardiovascular disease mortality in middle-aged men. JAMA. 2002;288:2709-16.

6. Laaksonen DE, Lakka HM, Niskanen LK, Kaplan GA, Salonen JT, Lakka TA. Metabolic syndrome and development of diabetes mellitus: application and validation of recently suggested definitions of the metabolic syndrome in a prospective cohort study. Am J Epidemiol. 2002;156:1070-7.

7. Liese AD, Mayer-Davis EJ, Haffner SM. Development of the multiple metabolic syndrome: an epidemiologic perspective. Epidemiol Rev. 1998;20:157-72.

8. Feng $Y$, Hong $X$, Li Z, Zhang W, Jin D, Liu X, et al. Prevalence of metabolic syndrome and its relation to body composition in a Chinese rural population. Obesity (Silver Spring). 2006;14:2089-98.

9. Gu D, Reynolds K, Wu X, Chen J, Duan X, Reynolds RF, et al. Prevalence of the metabolic syndrome and overweight among adults in China. Lancet. 2005;365:1398-405.

10. Szymańska E, Bouwman J, Strassburg K, Vervoort J, Kangas AJ, Soininen P, et al. Gender-dependent associations of metabolite profiles and body fat distribution in a healthy population with central obesity: towards metabolomics diagnostics. OMICS. 2002;16:652-67. 
11. Shah RV, Murthy VL, Abbasi SA, Blankstein R, Kwong RY, Goldfine AB, et al. Visceral adiposity and the risk of metabolic syndrome across body mass index: the MESA study. JACC Cardiovasc Imaging. 2014;7:1221-35.

12. Djibo DA, Araneta MR, Kritz-Silverstein D, Barrett-Connor E, Wooten W. Body adiposity index as a risk factor for the metabolic syndrome in postmenopausal Caucasian, African American, and Filipina women. Diabetes Metab Syndr. 2015;9:108-13.

13. Zhu S, Wang Z, Shen W, Heymsfield SB, Heshka S. Percentage body fat ranges associated with metabolic syndrome risk: results based on the third National Health and nutrition examination survey (1988-1994). Am J Clin Nutr. 2003;78:228-35.

14. Liu P, Ma F, Lou H, Liu Y. The utility of fat mass index vs. body mass index and percentage of body fat in the screening of metabolic syndrome. BMC Public Health. 2013;13:629.

15. Grundy SM. Metabolic syndrome scientific statement by the American Heart Association and the National Heart, Lung, and Blood Institute. Arterioscler Thromb Vasc Biol. 2005;25:2243-4.

16. Cook S, Weitzman M, Auinger P, Nguyen M, Dietz WH. Prevalence of a metabolic syndrome phenotype in adolescents: findings from the third National Health and nutrition examination survey, 1988-1994. Arch Pediatr Adolesc Med. 2003;157:821-7.

17. Ma GS, Ji CY, Ma J, Mi J, Yt SR, Xiong F, et al. Waist circumference reference values for screening cardiovascular risk factors in Chinese children and adolescents. Biomed Environ Sci. 2010;23:21-31.

18. Mi J, Wang TY, Meng LH, Zhu GJ, Han SM, Zhong Y, et al. Development of blood pressure reference standards for Chinese children and adolescents. Chin J Evid Based Pediatr. 2010;5:4-14.

19. Isomaa B, Almgren P, Tuomi T, Forsén B, Lahti K, Nissén M, et al. Cardiovascular morbidity and mortality associated with the metabolic syndrome. Diabetes Care. 2001;24:683-9.

20. Chen J, Muntner P, Hamm LL, Jones DW, Batuman V, Fonseca V, et al. The metabolic syndrome and chronic kidney disease in U.S. adults. Ann Intern Med. 2004:140:167-74.

21. Li Cl, Kardia SL, Liu CS, Lin WY, Lin CH, Lee YD, et al. Metabolic syndrome is associated with change in subclinical arterial stiffness: a community-based Taichung community health study. BMC Public Health. 2011;11:808.

22. Haffner SM, Valdez RA, Hazuda HP, Mitchell BD, Morales PA, Stern MP. Prospective analysis of the insulin-resistance syndrome (syndrome X). Diabetes. 1992;41:715-22.

23. WHO. Obesity: preventing and managing the global epidemic. Report of a WHO consultation. World Health Organ Tech Rep Ser. 2000;894:1-xii.

24. Zhou BF. Effect of body mass index on all-cause mortality and incidence of cardiovascular diseases-report for meta-analysis of prospective studies open optimal cut-off points of body mass index in Chinese adults. Biomed Environ Sci. 2002;15:245-52.

25. Liu Y, Tong G, Tong W, Lu L, Qin X. Can body mass index, waist circumference, waist-hip ratio and waist-height ratio predict the presence of multiple metabolic risk factorsin Chinese subjects? BMC Public Health. 2011:11:35.

26. Kim JY, Oh S, Chang MR, Cho YG, Park KH, Paek YJ, et al. Comparability and utility of body composition measurement vs. anthropometric measurement for assessing obesity related health risks in Korean men. Int I Clin Pract. 2013:67:73-80.

27. Ashwell M, Gunn P, Gibson S. Waist-to-height ratio is a better screening tool than waist circumference and BMI for adult cardiometabolic risk factors: systematic review and meta-analysis. Obes Comorbidity Diagn. 2012;13:275-86.

28. Smith U. Abdominal obesity: a marker of ectopic fat accumulation. J Clin Invest. 2015;125(5):1790-2.

29. Wang X, Wu H, Long Z, Sun Q, Liu J, Liu Y, et al. Differential effect of se on insulin resistance: regulation of adipogenesis and lipolysis. Mol Cell Biochem. 2016;415:89-102.

30. Laurens C, Moro C. Intramyocellular fat storage in metabolic diseases. Horm Mol Biol Clin Invest. 2016;26:43-52.

\section{Submit your next manuscript to BioMed Central and we will help you at every step:}

- We accept pre-submission inquiries

- Our selector tool helps you to find the most relevant journal

- We provide round the clock customer support

- Convenient online submission

- Thorough peer review

- Inclusion in PubMed and all major indexing services

- Maximum visibility for your research

Submit your manuscript at www.biomedcentral.com/submit
C Biomed Central 